\title{
LA DISTINCIÓN TEÓRICO/OBSERVACIONAL: ¿FAVORECE O PERJUDICA AL REALISMO CIENTÍFICO?
}

\author{
Christián C. CARMAN \\ Instituto de Estudios sobre la Ciencia y la Tecnología \\ Universidad Nacional de Quilmes \\ Consejo Nacional de Investigaciones Científicas y Técnicas \\ ccarman@unq.edu.ar
}

RESUMEN: Laudan denuncia una paradoja que recae sobre el realista científico. Por un lado, necesita la distinción teórico/observacional para definir su posición pero, por otro, la disolución de la distinción favorece su argumentación. En este artículo me propongo mostrar que si dentro de la distinción teórico/observacional se identifican dos dicotomías diferentes —una entre entidades observables y no observables y otra entre términos teóricos y no teóricos-, la paradoja se disuelve, pues para la caracterización del realismo hace falta la distinción entre términos teóricos y no teóricos, pero para su argumentación es conveniente la "disolución" de la distinción entre entidades observables y no observables.

PALABRAS CLAVE: paradoja, antirrealismo, Laudan, Harré

SUMMARY: According to Laudan, the scientific realist faces a paradox. On the one hand the realist needs the observational/theoretical distinction in order to define his own position but, on the other, the dissolution of the distinction is favourable for his argumentation. My purpose here is to show that if two different dichotomies are distinguished within the observational/theoretical distinction (one between theoretical and non-theoretical terms and the other between observable and non-observable entities) the paradox dissolves, since we need the first distinction for the characterization of the realism, but for its argumentation the "dissolution" of the second one is enough.

KEY WORDS: paradox, anti-realism, Laudan, Harré

Fundamentalmente, el realista sostiene que el éxito puede ser utilizado como una prueba de la verdad de las teorías, puesto que podemos observar directamente el éxito de una teoría, mas no su verdad.

Lewis 1991, p. $375^{*}$

\section{Introducción}

Muchos realistas han intentado defender el realismo argumentando a favor de que se disuelva la distinción teórico/observacional ya que, de

${ }^{*}$ En todos los casos en que aparece una cita en castellano de una obra en inglés cuya traducción no se menciona en la bibliografía, se debe suponer que la traducción es mía. Cuando el pasaje citado ha sido tomado de una versión publicada en castellano, los folios corresponden a dicha versión. 
esa manera, la posición instrumentalista ni siquiera podría formularse. Larry Laudan observa que dicha estrategia "se aproxima a lo paradójico", pues también un realismo de entidades teóricas necesita la distinción para poder ser caracterizado. En el presente trabajo analizaré la paradoja y la utilizaré como excusa para plantear la influencia en la formulación y defensa del realismo, que implica una presentación más clara de la distinción teórico/observacional. Para ello procederé a examinarla en tres partes. En la primera presentaré con cierto detalle la paradoja de Laudan; en la segunda propondré distinguir, dentro de la distinción teórico/observacional, dos dicotomías diferentes y mostraré cómo, con esa distinción en mente, la paradoja se disuelve y la posición realista puede caracterizarse con mayor precisión; y por último, en la tercera señalaré las ventajas que dicha distinción comporta para la posición realista.

\section{La paradoja de Laudan}

Es por todos conocida la gran dificultad que supone encontrar un factor común en lo que los realistas científicos afirman; sin embargo, no parece tan complicado lograr algún acuerdo respecto de aquello acerca de lo cual lo afirman. ${ }^{1}$ En general podríamos decir que el realista suele atribuir cierta propiedad epistémica (o metafísica) $E$ a la parte teórica de la ciencia o a la teórica y observacional, ${ }^{2}$ pero no exclusivamente a la observacional. ${ }^{3}$ Esta propiedad puede ser la verdad o verdad aproximada, la referencia, la existencia, ${ }^{4}$ la independencia de la mente, etc. Quien la predicara exclusivamente de la parte observacional o afirmara que no hay razones para predicarla de la parte teórica sería considerado, sin duda, un antirrealista; tal es el caso de van Fraassen y Laudan. De aquí se sigue que para una adecuada caracterización del realismo hace falta la distinción teórico/observacional.

Sin embargo, entre los críticos de la distinción se encuentran no pocos realistas. En efecto, muchos de ellos han celebrado la disolución de la distinción como una contribución importante para la defensa de su realismo. El caso paradigmático es el famoso artículo

\footnotetext{
${ }^{1}$ Cfr. Carman 2005, donde distingo hasta 1111 formas diferentes de realismo científico.

${ }^{2}$ Cfr. Ellis 1979, p. 28; Boyd 1984, p. 41; Hacking 1983, p. 26.

${ }^{3}$ Leplin 1984, pp. 1-2; Boyd 1984, p. 41; Putnam 1975, pp. 69 y s.; van Fraassen 1980, p. 24; Hacking 1983, pp. 26-27; Laudan 1981, p. 220; Jones 1991, p. 185.

${ }^{4}$ Poniendo entre paréntesis, por supuesto, el problema de si la existencia es una propiedad.
} 
de Maxwell (1962), en el cual intenta refutar al instrumentalismo. El instrumentalista sostiene que sólo puede hablarse de existencia en sentido estricto respecto de los referentes de los términos observacionales, pero que los términos teóricos deben ser considerados sólo útiles ficciones. Esta posición supone, por lo tanto, la clara distinción entre términos teóricos y observacionales. La estrategia de Maxwell consiste en mostrar que no es posible trazar una distinción clara y precisa entre lo observable y lo no observable, ya que sólo se trata de una cuestión de grados. Para ello muestra una serie continua en las observaciones que va desde observar en el vacío hasta mirar a través de un poderoso microscopio. Un año antes, Rom Harré había introducido una propuesta de continuidad observacional muy parecida. ${ }^{5}$ Maxwell concluye que, puesto que la distinción teórico/observacional está en función de nuestras capacidades fisiológicas, del estado de nuestro conocimiento y de los instrumentos con los que en ese momento contamos, no puede tener ningún significado ontológico (Maxwell 1962, p. 15). No cabe duda, entonces, de que —al menos en su discusión con el instrumentalismo- al realismo le es muy conveniente la disolución de la distinción teórico/observacional.

Ahora bien, si el realista necesita la distinción para formular su posición pero, a la vez, a él le conviene su disolución para defender su posición, la situación — como dice Laudan- se aproxima a lo paradójico. Veámoslo en las palabras del mismo Laudan:

La mayor parte de los realistas (v.g., Maxwell, Sellars, Popper y Putnam) sostiene que el colapso de la dicotomía teoría/observación mina al instrumentalismo y facilita el camino para el realismo sobre las entidades teóricas. Debe observarse que esta manera de establecer las cosas se aproxima a lo paradójico, puesto que un realismo "sobre las entidades teóricas" parecería presuponer la misma distinción de cuyo colapso se felicita. (Laudan 1990, p. 25)

En efecto, a menos que se utilice la salida wittgensteiniana que consiste en que el realista retira la escalera de la distinción teórico/observacional una vez que ha subido y antes de que el instrumentalista intente poner un pie sobre ella, la paradoja parece incontestable.

\section{La distinción de las distinciones}

Sin embargo, el grado de compromiso que un realista y un instrumentalista tienen con la distinción es muy distinto. El realista, como

\footnotetext{
${ }^{5}$ Cfr. Harré 1961, pp. 58-59.
} 
he dicho — enseguida profundizaré en esta idea-, predica la misma propiedad $E$ tanto de los observables como de los teóricos, mientras que el instrumentalista la predica sólo de los observables. Así, su compromiso con la distinción es mayor, ya que sin ella no podría definir su posición. ${ }^{6}$ Pero, si bien es cierto que el realista científico predica la propiedad $E$ principalmente de la parte teórica, no es que lo haga exclusivamente, por lo que su posición sería en principio reformulable sin necesidad de la distinción. De todas maneras, no es fundamental resolver esta cuestión porque, como se verá, la distinción - entendida como a continuación detallaré- puede trazarse y, además, tanto el realismo como el antirrealismo son realmente interesantes en la medida en que hablan de los teóricos, por lo que la distinción sigue siendo conveniente.

\subsection{La distinción de las distinciones}

Yehoshua Bar-Hillel (1970) sostuvo, al igual que Maxwell, que la distinción entre términos teóricos y observacionales no debe trazarse, aunque la razón en la que se fundamenta es muy distinta de la de Maxwell.

Bar-Hillel afirma que la distinción teórico/observacional es el resultado de confundir dos dicotomías que, si bien en algún sentido están relacionadas, son claramente diferentes: la dicotomía entre observable e inobservable y la dicotomía entre teórico y no teórico. La segunda divide entre aquellos términos que tienen significado sólo dentro del marco de una determinada teoría (términos teóricos) y aquellos cuyo significado puede conocerse independientemente de la teoría (términos no teóricos). ${ }^{7}$

\footnotetext{
${ }^{6}$ Sin embargo, no sería difícil esquivar la necesidad de una distinción nítida entre observables y no observables para mantener cierto instrumentalismo, con tal que uno tenga claro de qué lado prefiere arriesgarse. Así, (Muller 2004, p. 85) sostiene que, mientras se acepte como imperativo que, en los casos ambiguos acerca de la observabilidad, el filósofo se mantendrá al nivel de la aceptación (y no de la creencia), el empirismo constructivista puede seguir manteniéndose sin dificultad.

${ }^{7}$ Varios trabajos de la década anterior ya anticipaban implícitamente que se trataba de dos distinciones. En particular se destaca el muy influyente trabajo de Putnam (1962) donde afirma: "Un término teórico propiamente dicho es un término que proviene de una teoría científica (y el problema apenas tocado, en treinta años que se lleva escribiendo acerca de los 'términos teóricos', es qué es lo realmente distintivo de dichos términos). En este sentido (y pienso que éste es el sentido importante para las discusiones acerca de la ciencia), "satélite', por ejemplo, es un término teórico, aun cuando las cosas a las que se refiere sean bastante observables" (p. 128, las cursivas son del autor). Achinstein (1965, p. 200), por su parte, afirmaba: "[U]no siempre debe especificar la teoría con respecto a la cual un término dado
} 
En Bar-Hillel todavía no hay un criterio de teoricidad muy elaborado, pero - como él mismo sugiere - no es caritativo exigirle un criterio a esa altura. ${ }^{8}$ Intuitivamente, si bien existen varias maneras en las que un término puede pertenecer a una teoría, podríamos decir que un término pertenece esencialmente si no tiene sentido fuera de la teoría o, con un poco más de precisión, si la extensión del término no puede determinarse a menos que las leyes fundamentales de la teoría —y quizá algunas de las leyes especiales también- se presupongan como verdaderas. Así, no tendría sentido hablar de genes fuera de la teoría genética, ni de moléculas fuera de la molecular, ni de átomos, fuerza, masa, campo, electrón, agujero negro, microbios, bacterias, virus, fuera de cada una de las teorías que los proponen. Ésta es la intuición que está detrás de la distinción entre términos T-teóricos y T-no teóricos que la concepción estructuralista ha propuesto, elaborado y explotado. ${ }^{9}$

Van Fraassen (1980), por su parte, ha hecho una distinción parecida cuando afirma que:

Los términos o los conceptos son teóricos (introducidos o adaptados para los propósitos de la construcción de teorías); los entes son observables o inobservables. Esto puede parecer un detalle pequeño, pero separa la discusión en dos preguntas: ¿Podemos dividir nuestro lenguaje en una parte teórica y una no teórica? Y, por otro lado, ¿podemos clasificar objetos y eventos en observables e inobservables? (Van Fraassen 1980, p. 30)

Tomando el criterio de teoricidad estructuralista, podemos responder positivamente a la primera de las preguntas de van Fraassen:

está o no está 'cargado de teoría'. Y parecería que un término podría recibir esta clasificación respecto de una teoría, pero no respecto de otra, aun cuando dicho término ocurra en ambas. Puesto que, en una teoría, el significado del término no podría entenderse a menos que los principios de la teoría fueran conocidos, aunque éste no necesariamente sería el caso para la otra teoría (o al menos podría haber diferencias de grado significativas). Por ejemplo, 'masa' podría ser considerado 'cargado de teoría' con respecto a la mecánica newtoniana, pero no con respecto a la teoría del átomo de Bohr, en la que también aparece, ya que puede ser entendido independientemente de la última teoría. [...] Lo máximo que podría hacerse sería citar teorías particulares y componer, para cada una, listas indicando qué términos serán considerados teóricos y cuáles no para esa teoría" (las cursivas son del autor). Pero es mérito de Bar-Hillel haberlo explicitado por primera vez.

${ }^{8}$ Cfr. Bar-Hillel 1970, pp. 267-269.

${ }^{9}$ La bibliografía sobre los principales trabajos puede encontrarse en Balzer y Moulines 1980, Balzer 1986, y el capítulo 8 de Balzer y Moulines 1996. 
podemos distinguir los términos teóricos de los no teóricos. Pero, teniendo en cuenta el artículo de Maxwell, parecería que la respuesta a la segunda pregunta — sobre la distinción observable/inobservabledebe ser negativa. Pero sólo parecería. En efecto, lo que Maxwell y Harré demuestran no es que no puede distinguirse entre observable e inobservable, sino que (a) los miembros a un lado de la división pueden pasar con el tiempo a la otra y (b) no es posible trazar una distinción clara entre lo observable a simple vista y lo observable de manera indirecta. Pero ellos no prueban — ni pretenden hacerloque todo sea de hecho observable (aunque no observado) y que, por lo tanto, la distinción se disuelva. ${ }^{10}$

Ahora bien, si ambas distinciones pueden sostenerse y, además, tienen criterios distintos, es posible que se produzcan dos combinaciones que, para los objetivos de este trabajo, son sumamente interesantes: términos teóricos de entidades observables y términos teóricos de entidades inobservables. En efecto, un término puede ser esencial a una teoría, pero la entidad a la que refiere puede ser o no observable. Sin duda, el electrón y la bacteria son términos teóricos, pero la última es una entidad observable, mientras que el primero no lo es. Esta posibilidad, como veremos enseguida, nos permitirá precisar la caracterización de la posición realista y antirrealista. ${ }^{11}$

\subsection{Caracterización del realismo}

Una vez hecha la distinción de las dicotomías, lo natural es preguntarse si el realismo habla de las entidades inobservables o de los

${ }^{10}$ Maxwell (1962, p. 13) sostiene: “[A] unque he afirmado que la línea entre lo observable y lo inobservable es difusa, que varía de un problema científico a otro, y que se está desplazando constantemente hacia el límite del espectro que corresponde a lo inobservable a medida que desarrollamos mejores medios de observación - mejores instrumentos - sería, sin embargo, necio minimizar la importancia de la base observacional, porque es absolutamente necesaria como base de confirmación para los enunciados que refieren a entidades que son inobservables en un momento dado" (las cursivas y la traducción son mías). Por su parte, lo que Harré intenta probar es justamente que hay continuidad óptica entre un okapi y un virus (ambos observables), pero no entre éstos y el electrón (que sí es inobservable): “Defenderé que esa continuidad familiar conecta a un 'okapi' y un 'virus' pero que no conecta al 'okapi' con el 'electrón' ni al 'virus' con el 'electrón' [... . Los experimentos no han establecido de hecho la conexión de continuidad familiar óptica entre el 'okapi' o el "virus', y el "electrón"” (Harré 1961, pp. 58-59). Cfr. también Menuge 1995, p. 68, donde intenta probar que cualquier argumento que trate de minar la confianza en la observación indirecta recaerá también sobre la observación directa, por lo que las dos están en las mismas condiciones.

${ }^{11}$ En Carman y Fernández 2004 tratamos con cierto detalle las relaciones entre las dos dicotomías. 
términos teóricos. Está claro que no habla de las entidades inobservables simpliciter, pues entre ellas estarían el amor, la justicia, Dios, los ángeles, el alma, etc. Si es realismo científico, tiene que hablar de los inobservables de la ciencia, es decir, de las entidades teóricas inobservables. Pero si — como Harré y Maxwell han demostradola observabilidad es dependiente del tiempo, habrá que definir para qué tiempo $t$ esos términos teóricos lo eran de entidades inobservables. Lo único que nos atrevemos a decir aquí es que ese tiempo $t$ debe necesariamente incluir el tiempo presente y no necesariamente excluir el tiempo pasado. Lo primero se debe a que difícilmente podría llamársele realista a quien predicara la propiedad $E$ sólo de las entidades que en algún momento han sido inobservables, pero que hoy ya no lo son, no pronunciándose o negando esa propiedad de las entidades teóricas actualmente inobservables.

Aclarado esto, se podría caracterizar la posición realista mediante dos tesis:

1. Los referentes de los términos teóricos que han sido inobservables en algún tiempo $t$ son tan reales como los observables. ${ }^{12}$

2. Que los observables sean reales quiere decir que existen independientemente del sujeto cognoscente.

Uniendo las dos tesis, el realista afirma que las entidades teóricas que para algún tiempo determinado (que incluye el actual) han sido inobservables, existen independientemente del sujeto cognoscente. La razón para desdoblar la caracterización del realismo en dos tesis es que esa manera permite comprender mejor el verdadero alcance de los argumentos del debate. En general, tanto los realistas como los antirrealistas sostienen la segunda tesis, y los realistas sólo la primera, por lo que habitualmente los argumentos del debate pretenden probar exclusivamente la primera de las tesis. En efecto, la inducción pesimista de Laudan (1981), suponiendo la propiedad $E$ para los observables, niega que haya razones para sostenerla respecto de los inobservables. En otros ejemplos, Giere piensa que

\footnotetext{
${ }^{12}$ Hemos presentado esta tesis suponiendo que la propiedad $E$ es la existencia (realidad) de las entidades teóricas e inobservables (para un tiempo $t$ ). Pero si la propiedad $E$ fuera otra, sería fácilmente traducible. Por ejemplo, si fuera la verdad aproximada, debería decir: "las proposiciones que incluyen términos teóricos que han sido inobservables en algún tiempo $t$ son tan aproximadamente verdaderas como aquellas que incluyen exclusivamente términos observacionales".
} 
es absolutamente innegable que estos físicos nucleares están produciendo y usando las partículas con aproximadamente las mismas propiedades atribuidas a los protones. Evidentemente no es innegable en el sentido cartesiano según el cual dudar de ello sería contradictorio; pero es innegable en el sentido más ordinario, según el cual no podríamos dudar que hay personas, computadoras, o grandes imanes en ese laboratorio. (Giere 1988, p. 125)

Kukla sostiene que

hablando autobiográficamente, mi actual estado de opinión acerca del debate del realismo científico puede ser representado como $(2 \& 3) \mathrm{V}$ $(-2 \&-3)$ [los objetos de la percepción del sentido común — como piedras y bastones - existen y también existen las entidades inobservables planteadas por las teorías científicas — como los electrones y los procesos mentales inconscientes-, o ninguna de las dos clases de entidades existe]. Creo que los objetos del sentido común y los teóricos están en el mismo bote, pero no estoy seguro de cuál sea ese bote. (Kukla 1988, p. 8$)^{13}$

Y el mismo Maxwell sostiene que

si hay algún fenomenista no reconstructivo entre [mis] lectores, [mi] propósito, en lo que a ellos concierne, habrá sido logrado en gran medida si conceden lo que [supongo] que la mayoría de ellos, de todas maneras, mantendría con firmeza, esto es, que las entidades teóricas no están en una situación peor que la de los así llamados objetos físicos observables. (Maxwell 1962, p. 12)

Una vez caracterizado el realismo teniendo en cuenta la distinción de las dicotomías, puede verse sin dificultad que la paradoja planteada por Laudan se disuelve.

\subsection{La disolución de la paradoja}

En efecto, se ve con claridad que lo que se necesita para caracterizar la posición y lo que hace falta, en cambio, para justificarla son tesis distintas, pero no contradictorias. Para la formulación de la posición realista hacen falta dos requisitos:

\footnotetext{
${ }^{13}$ Otros textos de Kukla que muestran el acuerdo entre su planteamiento y el nuestro pueden encontrarse en las páginas 4 y 8 .
} 
1. Una distinción nítida entre términos teóricos y no teóricos (que el estructuralismo provee sin mayores dificultades).

2. Que algunas entidades teóricas hayan sido inobservables en algún tiempo $t$, incluyendo el actual (tesis difícil de negar).

En cambio, para la argumentación del realismo no es conveniente la negación de ninguna de las tesis anteriores (lo que lo volvería paradójico), sino la afirmación de lo que podríamos llamar — siguiendo a Harré - la tesis del desplazamiento de la frontera entre lo observable y lo inobservable:

3. Algunas entidades teóricas que en algún tiempo $t$ eran inobservables, en otro tiempo $t^{\prime}$ se han vuelto observables.

Esta tesis ha sido ampliamente defendida por Harré, de hecho, la ha convertido en la premisa central de su argumentación a favor del realismo. ${ }^{14}$ Es cierto que, probablemente, cuando Laudan denuncia la paradoja, tiene en mente una tesis en parte distinta de la que hemos propuesto aquí. Seguramente Laudan piensa en la disolución de la distinción teórico/observacional que - es cierto- disolvería la posibilidad del realismo al mismo tiempo que destruiría el instrumentalismo. En ese sentido, la paradoja se mantiene pero, al menos en el caso de Harré y Maxwell, no es esa tesis la que han visto favorable a la argumentación realista.

La tesis del desplazamiento de la frontera, además de dificultar seriamente el planteo de un instrumentalismo, creemos que es central para abrir un nuevo campo de argumentación a favor del realismo. En lo que resta del trabajo trataremos de probar justamente eso.

\section{Ventaja para el realismo}

Como ya hemos dicho, el realista sostiene que una determinada propiedad epistémica o metafísica $E$ está presente no sólo en las entidades observables o las proposiciones que están formadas sólo por términos cuyos referentes son observables, sino también en aquellas entidades teóricas e inobservables o en las proposiciones que incluyen términos teóricos y no observacionales. La propiedad $E$, sin embargo, puede ser medida — si es una magnitud, como la verdad aproximada - o simplemente detectada — si no es mensurable, como

\footnotetext{
${ }^{14} \mathrm{El}$ argumento aparece en numerosas obras, pero la reconstrucción más prolija y detallada está en Harré 1996. Cfr. Carman 2001 y 2002 para una discusión del argumento de Harré.
} 
la existencia- en aquéllas pero no en éstas. En efecto, habitualmente no es posible medir la aproximación a la verdad o captar la referencia, la existencia, etc., en las entidades inobservables o en las proposiciones o términos que hablan de ellas. Conscientes de esto, los realistas han intentado encontrar alguna otra propiedad $P$ que sí sea mensurable o al menos detectable en las entidades inobservables o en las proposiciones respectivas y que, sin embargo, esté estrechamente vinculada a la propiedad $E$, de tal manera que se pueda garantizar la presencia de $E$ a partir de la medición de $P$ o de la detección de su presencia. Así, es posible una evaluación indirecta de la propiedad $E$ a partir de $P$. Como dice Lewis (1991, p. 375): "el realista sostiene que el éxito puede ser utilizado como una prueba de la verdad de las teorías, puesto que podemos observar directamente el éxito de una teoría, mas no su verdad". Algunos realistas han postulado que $P$ es la adecuación empírica, otros la propiedad de realizar predicciones sorprendentes, otros la plausibilidad ontológica, la coherencia con la ontología común de la ciencia, etc. Pero en todos los casos, la tarea más ardua del realista consiste en probar la estrecha relación entre $P$ y $E$.

El antirrealista tiene dos opciones para refutar esta argumentación. La primera es afirmar que para cada propiedad $P$ que el realista postule la historia de la ciencia muestra que $P$ y $E$ no han estado ligadas. El argumento paradigmático de esta clase es la inducción pesimista de Laudan. Nótese que el antirrealista no necesita medir ni detectar $E$ para saber que $P$ no acompaña a $E$, basta con mostrar que para varias teorías que tienen la propiedad $P$, sin embargo, si se sostiene que una tiene $E$, es necesario negar que la otra lo tiene; por ejemplo, haciendo ver que las leyes de las teorías se contradicen (si $E$ es la verdad), o que postulan entidades distintas e incompatibles entre sí (si $E$ es la referencia), etcétera.

La segunda opción del antirrealista es mostrar que cualquier argumentación a favor del vínculo entre $E$ y $P$ supone dicho vínculo, con lo que se cae en una petición de principio. Laudan (1981) y Fine (1984) han ensayado esta estrategia: el realista sostiene que la tesis realista es la que mejor explica el éxito de la ciencia y que, por lo tanto, el realismo debe ser verdadero, pero esto supone lo que se quiere demostrar: que el ser la mejor explicación de algo baste para suponer su verdad, es decir, supone que $P$ (ser la mejor explicación) y $E$ (ser verdadero) están vinculados. Magnus y Callender (2004) han presentado la última versión de la familia de objeciones que pretende que el realismo cae en una petición de principio afirmando que el 
argumento de la mejor explicación cae en una falacia estadística (la falacia de la proporción base).

\section{1. Causa de la dificultad}

Parecería que para el realista no hay escapatoria y, en efecto, así lo es si es cierto que, como suponen los realistas y los antirrealistas, la medición o detección de la propiedad $E$ es inaccesible en las entidades o proposiciones teóricas. Y esto no debe ser entendido en el sentido del genio maligno cartesiano, sino en el mismo sentido en el que, en cambio, la medición o detección de la misma propiedad sí nos es accesible en las entidades observables. Y la razón de esta inaccesibilidad es muy simple: descartado cualquier argumento a priori sobre el vínculo entre $P$ y $E$ (porque caería en petición de principio), lo único que resta es comparar $P$ y $E$ pero, para poder hacerlo, los dos términos de la comparación nos tienen que ser accesibles. $P$ lo es, pero $E$ no. Es decir, sabemos lo que la teoría dice sobre la entidad teórica, pero no sabemos si ésta es así. Ellis lo expresa con mucha claridad: "[n]osotros podemos investigar la naturaleza y desarrollar una comprensión teórica del mundo, pero no podemos comparar lo que creemos que sabemos con la verdad para ver qué tan bien lo estamos haciendo" (Ellis 1985, p. 69).

\subsection{Solución de la dificultad}

No obstante, si recordamos la distinción de las dicotomías que he planteado, debemos reconocer que la medición o detección de la propiedad $E$ es inaccesible en las entidades inobservables o las proposiciones no observacionales, no necesariamente en las teóricas y ésta es la clave del asunto. Pero — se me replicará-, el realismo interesante habla de las entidades teóricas e inobservables o de sus proposiciones; por lo tanto, que la propiedad $E$ nos sea inaccesible a causa de su inobservabilidad o de su teoricidad no es relevante porque, de todas maneras, son teóricas e inobservables y, en consecuencia, inaccesibles. Es cierto, como he dicho, que el realismo tiene que incluir esencialmente las entidades teóricas que actualmente son inobservables, pero también lo es - y aquí cobra importancia la tesis del desplazamiento de la frontera - que entidades que en el pasado eran inobservables hoy no lo son y que, por lo tanto, en ellas (y sólo en ellas) la vinculación entre la propiedad $E$ y la propiedad $P$ es mensurable o al menos detectable, puesto que $E$, allí, es accesible.

Está claro que la posibilidad de medir $E$ está restringida en la gran mayoría de los casos a entidades de teorías del pasado y que, por lo 
tanto, para las teorías actuales es todavía necesario encontrar una propiedad $P$ que sí sea mensurable o detectable actualmente. Pero lo relevante es que, si combinamos la distinción de las dicotomías con la tesis del desplazamiento de la frontera, la vinculación de $E$ y $P$ es mensurable o detectable en las teorías pasadas y, por lo tanto, se podría inducir a partir de allí la misma vinculación en las teorías en las que sólo puede medirse o detectarse $P$. Es éste, en esencia, el argumento inductivo que Harré propuso.

\subsection{Alcance de la ventaja}

Es importante aclarar hasta qué punto es una ventaja para el realismo que la tesis de la inaccesibilidad de la propiedad $E$ no sea válida para todo tiempo $t$. No es una ventaja en el sentido de inclinar necesariamente la balanza a favor del realismo. Esto debería analizarse empíricamente con mucho cuidado. Lo único que establece es que el vínculo entre $E$ y $P$ es empíricamente tratable. Aquí cobra su dimensión real la inducción pesimista de Laudan, por un lado, y el argumento inductivo de Harré, por el otro.

Pero sí constituye una ventaja la posibilidad de la medición o captación de $E$ en el sentido de que las argumentaciones realistas no necesariamente tienen que ser tan indirectas, tratando de probar a priori una vinculación estrecha entre $E$ y $P$. Puede sostenerse un realismo más contingente; como dice Harré, "el argumento deberá ser, finalmente, inductivo, puesto que es lógicamente posible que una teoría sea adecuada empíricamente, plausible ontológicamente y eficaz en la manipulación pero no verosímil" (Harré 1996, p. 141).

Esto es, puesto que es lógicamente posible que $P$ y $E$ no vayan juntas, habrá que mostrarlo empíricamente. La última respuesta es empírica. Habrá que ver si favorece al realismo.

\section{BIBLIOGRAFÍA}

Achinstein, P., 1965, "The Problem of 'Theoretical Terms", American Philosophical Quarterly, vol. 2, no. 3, pp. 193-203.

Balzer, W., 1986, "Theoretical Terms: A New Perspective", The Journal of Philosophy, vol. 83, no. 2, pp. 71-90.

Balzer, W. y C.U. Moulines, 1980, "On Theoreticity”, Synthese, vol. 44, pp. 467-494.

Balzer, W. y C.U. Moulines (comps.), 1996, Structuralist Theory of Science. Focal Issues, New Results, Walter de Gruyter, Nueva York. 
Bar-Hillel, Y., 1970, “Neorealism vs. Neopositivism. A Neo-Pseudo Issue", Aspects of Language, The Magnes Press/The Hebrew University, Jerusalén, pp. 263-272.

Boyd, R., 1984, “The Current Status of Scientific Realism”, en Leplin 1984, pp. $41-82$.

Carman, C.C., 2005, “Realismo científico' se dice de muchas maneras, al menos de 1111", Scientiae Studia, Revista Latino-Americana de Filosofia e História da Ciência, vol. 3, no. 1, pp. 43-64.

——, 2002, "Rom Harré, el problema de la inducción y el argumento del doble no-milagro", Revista Patagónica de Filosofía, año 3, vol. 3, no. 1, pp. 103-122.

—_ 2001, "El argumento inductivo de R. Harré: Un intento de superar la "petición de principio fundamental del Realista"", Epistemología e Historia de la Ciencia, vol. 7, no. 7, pp. 87-94.

Carman, C.C. y M.P. Fernández, 2004, "Gen: ¿̨teórico y observacional? Términos T-teóricos y términos 'T-observacionales'", en Martins et al. 2004, pp. 102-109.

Churchland, P.M. y C. Hooker (comps.), 1985, Images of Science, The University of Chicago Press, Chicago.

Ellis, B., 1985, "What Science Aims to Do", en Churchland y Hooker 1985, pp. $48-74$.

— 1979, Rational Belief Systems, Blackwell, Oxford.

Fine, A., 1984, “The Natural Ontological Attitude", en Leplin 1984, pp. 83107.

Giere, R., 1988, Explaining Science. A Cognitive Approach, The University of Chicago Press, Chicago.

Hacking, I., 1983, Representing and Intervening, Cambridge University Press, Cambridge. [Versión en castellano: Representar e intervenir, trad. Sergio Martínez, Paidós/Instituto de Investigaciones FilosóficasunAM, México, 1996.]

Harré, R., 1996, "From Observability to Manipulability: Extending the Inductive Arguments for Realism", Synthese, vol. 108, pp. 137-155.

—, 1961, Theories and Things, Sheed y Ward, Londres/Nueva York. [Versión en castellano: Teorías y cosas, trad. J. Vallverdú, Herder, Barcelona, 1965.]

Jones, R., 1991, "Realism about What?", Philosophy of Science, vol. 58, no. 2, pp. 185-202.

Kukla, A., 1998, Studies in Scientific Realism, Oxford University Press, Nueva York.

Laudan, L., 1990, Science and Relativism. Some Key Controversies in the Philosophy of Science, The University of Chicago Press, Chicago. [Versión en castellano: La ciencia y el relativismo, trad. J. Francisco Álvarez Álvarez, Alianza, Madrid, 1993.] 
Laudan, L., 1981, “A Confutation of Convergent Realism”, en Leplin 1984. (Publicado originalmente en Philosophy of Science, vol. 48, no. 1, 1981, pp. 19-49.)

Leplin, J., 1984, Scientific Realism, University of California Press, Berkeley.

Lewis, P., 1991, "Why the Pessimistic Induction Is a Fallacy", Synthese, vol. 129, no. 3, pp. 371-380.

Magnus, P.D. y C. Callender, 2004, "Realist Ennui and the Base Rate Fallacy", Philosophy of Science, vol. 71, pp. 320-338.

Martins, R.A., L.A.C.P. Martins, C.C. Silva, J.M.H. Ferreira (comps.), 2004, Filosofia e história da ciência no Cone Sul: $3^{\circ}$ Encontro, AFHIC, Campinas.

Maxwell, G. y H. Feigl (comps.), 1962, "The Ontological Status of Theoretical Entities", Minnesota Studies in the Philosophy of Science, vol. 3, University of Minnesota Press, Minneápolis, pp. 3-27. [Versión en castellano: "El estatus ontológico de las entidades teóricas", en L. Olivé y A.R. Pérez Ransanz, Filosofía de la ciencia: teoría y observación, trad. Marcela Cinta, León Olivé y Ana Rosa Pérez Ransanz, Siglo XXI, México, 1989, pp. 116-144.]

Menuge, A., 1995, "The Scope of Observation", The Philosophical Quarterly, vol. 45, no. 178, pp. 60-69.

Muller, F.A., 2004, "Can a Constructive Empiricist Adopt the Concept of Observability?", Philosophy of Science, vol. 71, pp. 80-97.

Nagel, E., P. Suppes, y A. Tarski (comps.), 1962, Logic, Methodology and Philosophy of Science, Stanford University Press, Stanford.

Putnam, H., 1975, Mathematics, Matter and Method, vol. 1, Cambridge University Press, Cambridge.

- 1962, "What Theories Are Not", en Nagel, Suppes y Tarski 1962, pp. 240-252. [Versión en castellano: "Lo que las teorías no son", trad. Elia Nathan, en Rolleri 1986, pp. 127-139.]

Rolleri, J.L., 1986, Estructura y desarrollo de las teorías científicas, UNAM, México.

Van Fraassen, B.C., 1980, The Scientific Image, Oxford University Press, Oxford. [Versión en castellano: La imagen científica, trad. Sergio Martínez, Paidós/Instituto de Investigaciones Filosóficas-UnAM, México, 1996.]

Recibido el 6 de diciembre de 2004; revisado el 24 de octubre de 2005; aceptado el 9 de noviembre de 2005. 